\title{
Karyotypic Variations in Three Indian Species of the Genus Rana (Anura: Ranidae) from the Western Ghats, India
}

\author{
S. Hareesh Joshy ${ }^{1 *}$, Mitsuru Kuramoto ${ }^{2}$, K .S. Sreepada ${ }^{3}$ and \\ M. Abdul Rahiman ${ }^{4}$ \\ ${ }^{1}$ Rondano Biodiversity Research Laboratory, St. Aloysius College, Mangalore-575003, India \\ ${ }^{2}$ 3-6-15 Hikarigaoka, Munakata, Fukuoka, 811-3403, Japan \\ ${ }^{3}$ Department of Applied Zoology, Mangalore University, Mangala Gangotri-574199 India \\ ${ }^{4}$ Halcyon, Kaprigudda, New Road, Mangalore-1, Karnataka, India
}

Received December 8, 2005; accepted December 22, 2005

\begin{abstract}
Summary The karyotype and C-banding analysis of somatic metaphase chromosomes were attempted on 3 species of Indian frogs (Rana curtipes, $R$. temporalis, R. malabarica) which are distributed in the Western Ghats, Southwest India. All had $2 n=26$ chromosomes with invariably 5 pairs of large and 8 pairs of small chromosomes. Metacentric and submetcentric chromosomes were found in the complement, the former more common than the latter. A secondary constriction with a prominent satellite in the short arm of nos. 10 and 12 chromosomes are unique only in R. curtipes. The Cpositive telomeric bands were localized in the short arms of nos. 9 and 10 chromosomes of R. temporalis. Non-centric C-positive bands were observed in the distal half of the long arm of no. 10 chromosome of $R$. malabarica. None of the 3 species had an identifiable sex chromosome. There were variations in the centromeric position and secondary constriction of chromosome pair nos. 2, 3, 4, 5, 9,11 and 12 . These variations might have arisen due to pericentric inversions. It seems likely from the inversion studies that $R$. curtipes and $R$. temporalis are chromosomally more closely related than R. malabarica. Comparative account of karyotypes are discussed.
\end{abstract}

Key words Anurans, Karyotype, C-bands

The Western Ghats are one of the hotspot of amphibian biodiversity comprising 123 species (Sanjay 1997). But only very few species of anurans have been cytogenetically worked out. Among the Indian ranid frogs belonging to the large and prominent family Ranidae only 5 species have been cytogenetically investigated. Euphlyctis cyanophlyctis was studied from South India (Natarajan 1958), from Punjab (Mittal and Sawhney 1971) and Chandigarh (Yadav and Pillai 1975). Euphlyctis hexadactylus was studied by Natarajan (1958). Haplobatrachus tigerinus was studied by Asana and Kharadi (1937), Chakrabarti et al. (1983) and Sharma et al. (1966). Rana temporalis and R. curtipus was reported by Joshy et al. (1999). However no previous studies have provided Cbanding data for Indian frogs except H. tigerinus (Rana tigrina) by Yadav and Pillai (1975). Hence we carried out a comparative studies of non-banded and C-banded karyotypes of 3 species of the genus Rana from the Western Ghats, India. The karyotype of $R$. malabarica is here reported for the first time.

Materials and methods

Three species of anurans, Rana curtipes, $R$. temporalis, and $R$. malabarica were collected for cytogenetic analysis from Madikeri, Karnataka, in the Western Ghats, India. Individual frogs were

*Corresponding author, e-mail: shjoshy@yahoo.co.in 
Table 1. Mean relative length and centromeric index of chromosome in three species of the genus Rana $(2 n=26)$

\begin{tabular}{|c|c|c|c|c|c|c|}
\hline \multirow{2}{*}{ Pair No. } & \multicolumn{3}{|c|}{ 1. Relative length (mean \pm S.D) } & \multicolumn{3}{|c|}{ 2. Centromeric index $($ mean \pm S.D) } \\
\hline & R. curtipes & R. temporalis & R. malabaricus & R. curtipes & R. temporalis & R. malabaricus \\
\hline 1. & $13.09 \pm 0.21$ & $14.94 \pm 0.78$ & $14.16 \pm 0.16$ & $47.45 \pm 2.92 \mathrm{~m}$ & $44.42 \pm 0.70 \mathrm{~m}$ & $45.38 \pm 0.31 \mathrm{~m}$ \\
\hline 2. & $11.25 \pm 0.11$ & $12.16 \pm 0.65$ & $12.09 \pm 0.23$ & $37.07 \pm 2.46 \mathrm{sm}$ & $39.79 \pm 0.60 \mathrm{~m}$ & $36.20 \pm 0.13 \mathrm{sm}$ \\
\hline 3. & $10.41 \pm 0.43$ & $11.03 \pm 0.32$ & $11.41 \pm 0.45$ & $42.19 \pm 0.04 \mathrm{~m}$ & $31.37 \pm 0.50 \mathrm{sm}$ & $35.95 \pm 2.54 \mathrm{sm}$ \\
\hline 4. & $9.94 \pm 0.19$ & $10.60 \pm 0.41$ & $10.27 \pm 0.42$ & $35.19 \pm 2.51 \mathrm{sm}$ & $42.29 \pm 3.44 \mathrm{~m}$ & $36.84 \pm 1.40 \mathrm{sm}$ \\
\hline 5. & $9.15 \pm 0.35$ & $9.99 \pm 0.57$ & $9.63 \pm 0.30$ & $45.58 \pm 1.30 \mathrm{~m}$ & $42.71 \pm 1.37 \mathrm{~m}$ & $36.15 \pm 2.51 \mathrm{sm}$ \\
\hline 6. & $7.48 \pm 0.28$ & $6.31 \pm 0.24$ & $6.69 \pm 0.43$ & $47.50 \pm 2.01 \mathrm{~m}$ & $45.87 \pm 2.82 \mathrm{~m}$ & $43.84 \pm 2.67 \mathrm{~m}$ \\
\hline 7. & $6.67 \pm 0.16$ & $6.09 \pm 0.24$ & $6.07 \pm 0.10$ & $47.21 \pm 2.24 \mathrm{~m}$ & $42.96 \pm 1.49 \mathrm{~m}$ & $42.83 \pm 2.07 \mathrm{~m}$ \\
\hline 8. & $6.13 \pm 0.13$ & $5.77 \pm 0.25$ & $5.62 \pm 0.19$ & $45.27 \pm 1.21 \mathrm{~m}$ & $44.93 \pm 2.82 \mathrm{~m}$ & $42.39 \pm 0.25 \mathrm{~m}$ \\
\hline 9. & $5.74 \pm 0.26$ & $5.57 \pm 0.16$ & $5.23 \pm 0.30$ & $44.99 \pm 0.98 \mathrm{~m}$ & $43.76 \pm 0.88 \mathrm{~m}^{*}$ & $21.45 \pm 2.25 \mathrm{st}$ \\
\hline 10. & $5.39 \pm 0.12$ & $5.20 \pm 0.19$ & $4.99 \pm 0.24$ & $45.56 \pm 2.65 \mathrm{~m}^{*}$ & $42.76 \pm 2.44 \mathrm{~m}^{*}$ & $48.27 \pm 2.91 \mathrm{~m}$ \\
\hline 11. & $5.28 \pm 0.07$ & $4.90 \pm 0.18$ & $4.81 \pm 0.16$ & $35.47 \pm 0.12 \mathrm{sm}$ & $46.08 \pm 2.21 \mathrm{~m}$ & $22.89 \pm 2.09 \mathrm{st}$ \\
\hline 12. & $4.90 \pm 0.59$ & $4.77 \pm 0.37$ & $4.63 \pm 0.31$ & $31.24 \pm 0.21 \mathrm{sm}^{*}$ & $33.09 \pm 1.03 \mathrm{sm} *$ & $46.56 \pm 0.20 \mathrm{~m}^{*}$ \\
\hline 13. & $4.78 \pm 0.36$ & $3.97 \pm 0.30$ & $4.19 \pm 0.31$ & $42.87 \pm 2.99 \mathrm{~m}$ & $40.05 \pm 2.72 \mathrm{~m}$ & $43.97 \pm 2.87 \mathrm{~m}^{*}$ \\
\hline
\end{tabular}

Abbreviations $\mathrm{m}$, sm and st indicate metacentric, submetacentric and subtelocentric, respectively and asterisks show chromosome with C-positive satellites region. C: centrometric. $\mathrm{P}^{\mathrm{d}}$ : short arm distal.

injected intraperitonially with colchicine solution $(0.1 \%)$ to the final concentration of $0.05 \%$ per gram body weight. They were sacrificed after $17 \mathrm{~h}$.

Chromosome spreads were prepared from bone marrow cells using Omura's (1967) methods. Differential staining for localization of C-bands in chromosomes was carried out using the method of Sumner (1972). Chromosomes were measured using dial calipers and arranged in the decreasing order of size, and centromeric position of chromosomes following the methods of Levan et al. (1964). There was no discernible sex chromosome in the species studied. Therefore, measurements from both sexes had been pooled together for numerical analysis. Both non-banded and C-banded karyotypic data of these species are compared to find out chromosomal rearrangements. The variations in distribution and amount of heterochromatin have been calculated.

\section{Results and discussion}

The chromosomal complements of $R$. curtipes, $R$. temporalis and $R$. malabarica were similar in $2 n=26$. The chromosomes of these species can be grouped into 2 distinct sizes, 5 large chromosome pairs (nos. 1-5) and 8 medium to small chromosome pairs (nos. 6-13) which make up more than $53 \%$ and less than $47 \%$ relative length of the complements, respectively. The relative length and nature of chromosomes are given in Table 1 and the non-banded and C-banded karyotypes are provided in Figs. 1, 2. The chromosomes that are involved in rearrangements are shown in idiograms (Fig. 4).

\section{Rana curtipes}

The diploid chromosome number was 26 (Fig. 1A). All the chromosomes were biarmed and consequently $\mathrm{FN}=52$ with mean relative length ranging from 13.09 to 4.78 . Chromosome nos. 2, 4, 11 and 12 were submetacentric and the rest were metacentric (Table 1). There were 2 marker chromosome pairs, pair no. 10 had a distinct satellite either in a heteromorphic or homomorphic state in the short arm and pair no. 12 also had a satellite in the short arm of the chromosome. The localization and distribution of C-bands are evident from Fig. 2A. The satellite regions of nos. 10 and 12 chromosomes were C-positive. 

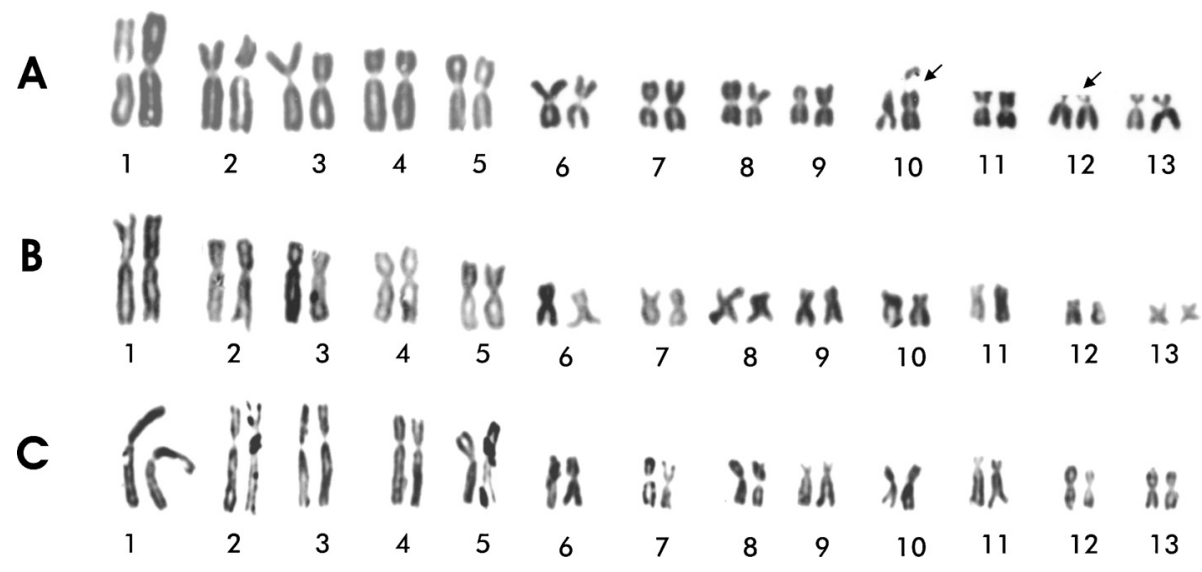

Fig. 1. Non-banded karyotype of Rana Curtipes (A), Rana temporalis (B) and Rana malabarica (C) (arrow indicates the marker chromosome).

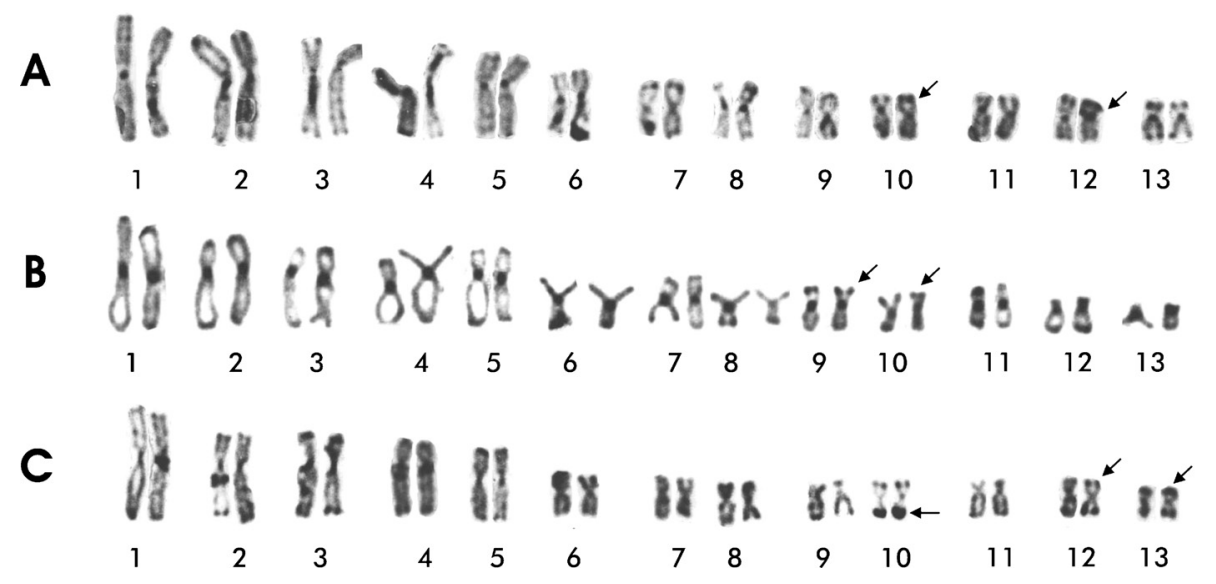

Fig. 2. $\mathrm{C}$ banded karyotypes of $R$. curtipes (A), R. temporalis (B) and R. malabarica (C) (arrow indicates the marker chromosome).

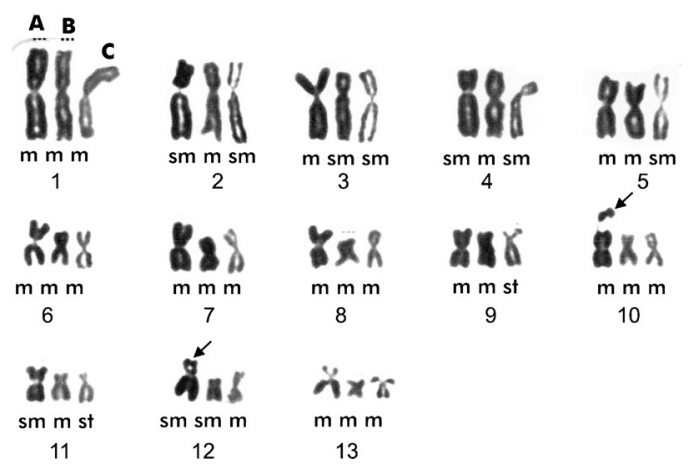

Fig. 3. Karyotypic comparison of 3 species of the genus $R$. curtipes (A), R. temporalis (B) and R. malabarica (C). (arrow indicates the marker chromosome).

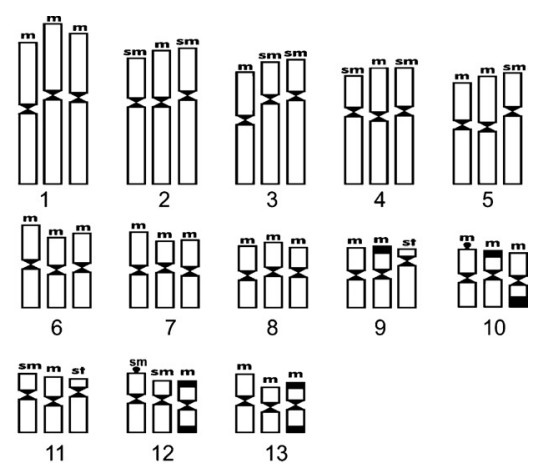

Fig. 4. Idiogram comparison of 3 species of the genus $R$. curtipes (A), R. temporalis (B) and $R$. malabarica $(\mathrm{C})$. (arrow indicates the marker chromosome). 


\section{Rana temporalis}

Enumeration of chromosomes in the metaphase plates of the males and females indicated the presence of 26 biarmed elements (Fig. 1B). The FN is 52. Categorization of chromosomes with karyometric data (Table 1) revealed 11 pairs of metacentric (nos. 1, 2, 4 to 11 and 13) and 2 pairs of submetacentric chromosomes (nos. 3 and 12). The mean relative length ranged from 14.94 to 3.97 .

The pattern of $\mathrm{C}$-band localization reflecting the constitutive heterochromatin regions of the karyotype is discernible from Fig. 2B. All the chromosomes except nos. 9 and 10 displayed similar arrangement where in the $\mathrm{C}$-positive chromatin is confined to the centromeric regions. In nos. 9 and 10 the telomeric ends of the short arms were distinctly C-positive.

\section{Rana malabarica}

All chromosomes are biarmed and FN=52 (Fig. 1C). Analysis of karyotypes and measurement of chromosomes indicated the presence of seven pairs of metacentric (nos. 1, 6, 7, 8, 10, 12 and 13) 4 pairs of submetacentric (nos. 2-5) and 2 pairs of subtelocentric (nos. 9 and 11) chromosomes. The mean relative length ranged from 14.16. to 4.19. The C-banded karyotypes (Fig. 2C) showed that chromosome pair nos. 10, 12 and 13 could be distinguished by the content and distribution of C-positive telomeric region in the short arm and long arm.

A perusal of the previous karyological literature shows that the family Ranidae is rather uniform in the karyotypes. So far about 75 species of the genus Rana have been cytogenetically studied from various continents which reveals that most common diploid number is 26. Only $R$. arvalis (Wickbom 1945), R. chensinensis (Witschi et al. 1958), R. dybowskii (Nishioka et al. 1987) and $R$. ornativentris (Kobayashi 1962, Seto 1965) have $2 n=24$. Whether the $2 n$ is 24 or 26 , the majority of these species have biarmed metacentric or submetacentirc chromosomes and subtelocentric chromosomes occur less frequently. In the present study subtelocentric chromosomes were observed in nos. 9 and 11 chromosomes of $R$. malabarica. Only 2 species, $R$. muscosa $(2 n=26)$ and $R$. ornativentris $(2 n=24)$, have telocentric chromosomes in their karyotypes (Haertel et al. 1974, Nishioka et al. 1987). Seto (1965) observed karyotypes of $R$. japonica, $R$. nigromaculata, $R$. rugosa and $R$. catesbeiana which had 5 pairs of large and 8 pairs of small chromosomes. Koref-Santibanez (1979) also reported 5 pairs of large and 8 pairs of small chromosomes in $R$. lessonae and $R$. ridibunda. The first group constitutes more than $50 \%$ of the relative length of the chromosome complements. In the present analysis the 3 species had $2 n=26, \mathrm{FN}=52$ and the karyotypes show 5 large and 8 medium to small chromosomes. In this respect the chromosomes of these 3 species resembled those of the other ranid species reported earlier. In spite of their apparent similarity the karyotypes of these species diverged from each other, as evidenced by variation in the centromeric position and secondary constriction of chromosome pair nos. 2, 3, 4, 5, 9, 11 and 12. R. curtipes showed centromeric disposition more frequently than the other species. $R$. temporalis on the other hand seems to have undergone less frequent chromosomal changes. Similar kinds of chromosomal rearrangements were reported by Vences et al. (2000). Nearly 50\% of the chromosome are involved in rearrangement.

Chromosome nos. 10 and 12 in the short arm of $R$. curtipes exhibited secondary constriction either in the heteromorphic condition or in the homomorphic condition. The presence of NORs in chromosome pair no. 10 is typical for most species of the genus Rana. R. palustris was shown to have 3 NORs (Schmid 1980). The NORs had been maintained in chromosome evolution of the Rana species.

In many ranid species where C-banding analysis has been done (Heppich 1978, Heppich and Tunner 1979, Iizuka 1989, Miura 1994, Odierna et al. 2001), it has been shown that the C-heterochromatin is confined to the centromere (Schmid 1978). The present investigation agrees with the earlier observations except in $R$. curtipes and $R$. temporalis. The centromeric regions of all chromosomes were C-positive, chromosome nos. 7, 9, 10, 12 and 13 showed additional C-positive chromat- 
ic regions which were specific for each species, while $R$. curtipes had C-positive telomeric regions in the short arm of nos. 7 and 13 chromosomes and C-positive satellites in nos. 10 and 12 chromosomes. C-positive telomeric bands were localized in the short arms of nos. 9 and 10 chromosome of $R$. temporalis. Telomeric bands were also seen in the short arm of chromosome nos. 3 and 5 , of $R$. ridibunda, $R$. esculenta and $R$. lessonae (Heppich 1978). Terminal heterochromatin region associated with smaller arms in no. 9 was observed in Hoplobatrachus tigerinus (Yadav and Pillai 1975) and non-terminal positions in Hyla japonica (Seto 1964). Non centromeric C-positive bands were more extensive in. $R$ malabarica than the other two species.

\section{Karyotypic comparison of Rana species}

Scrutiny of the composite karyotype (Fig. 3), the composite C-banded idiogram (Fig. 4) and comparative data pertaining to relative length and centromeric index of chromosomes of the three Rana species (Table 1), indicated that these species share a common diploid number 26. While the relative length of the chromosomes is approximately comparable, only 8 pairs of chromosomes (Nos. 1, 4, 6, 7, 8, 10, 12 and 13) compare well for the position of centromere among the species. In contrast chromosome nos. 3, 5, 9 and 11 exhibited variation in centromeric positions as given below.

Chromosome 3: Metacentric in R. curtipes but submetacentric in other species

Chromosome 5: Submetacentric in $R$. malabarica and metacentric in other species

Chromosome 9: Subtelocentric in R. malabarica and metacentric in other species

Chromosome 11: Submetacentric in R. curtipes, metacentric in $R$. temporalis and subtelocentric in R. malabarica

Possession of a marked secondary constriction with a prominent satellite in the short arms of nos. 10 and 12 chromosome is unique only for $R$. curtipes.

While the centromeric regions of all chromosomes were C-positive, chromosome nos. 7, 9, 10, 12 and 13 showed additional C-positive chromatin regions which were specific for each species. While $R$. curtipes had C-positive telomeric regions in the short arms of nos. 7 and 13 chromosomes and C-positive satellite in nos. 10 and 12 and C-positive telomeric bands were localized in the short arms of nos. 9 and 10th chromosomes of $R$. temporalis. Non centromeric C-positive bands were more extensive in $R$. malabarica than the other 2 species. The no. 10 chromosome had a C-positive block in the distal half of the long arm in addition to the C-positive telomeric band in the short arm. The no. 12 chromosome showed C-positive band distally in both arms. The no. 13 chromosome also exhibited telomeric C-positive bands in both arms.

Thus, more extensive amount of heterochromatin is seen in $R$. temporalis than in other 2 species. However, significant relation could not be established between the role of heterochromatin and the chromosomal evolution involved in these 3 species of the genus Rana.

\section{Acknowledgements}

We thank Rev. Father Prashant Madtha, Principal, St. Aloysius College, Mangalore for providing all the facilities in the Rondano Biodiveristy Research Laboratory. Thanks are due to Rev. Father Leo D'Souza, Director of Applied Biology Laboratory at St. Aloysius College for his guidance and encouragement. We thank Siju, Pradeep Salin and Soloman Alva for their help in the field work.

\section{References}

Asana, J. J. and Kharadi, R. G. 1937. Chromosomes of Rana tigrina Boul. Current Science 5: 649.

Chakrabarti, S., Banerjee, N., Neogi, L. N. and Roy-Choudhuri, S. 1983. C-band positive W-chromosome in the female Indian frog. Experientia 39: 321-322. 
Haertel, J. D., Owczarzak, A. and Storm, R. M. 1974. A comparative study of the chromosomes from five species of the genus Rana (Amphibia: Salientia). Copeia 1974: 109-114.

Heppich, S. 1978. Hybridogenesis in Rana esculenta: C-band karyotypes of Rana ridibunda, Rana lessonae and Rana esculenta. Z. Zool. Syst. Evolut. Forsch. 16: 27-39.

— and. Tunner, H. G. 1979. Chromosomal constitution and C-banding in homotypic Rana esculenta crosses. Mitt. Zool. Mus. Berlin. 55: 111-114.

Iizuka, K. 1989. Constitutive heterochromatin and nucleolus organizer regions in Japanese brown frogs, Rana japonica and Rana ornativentris. Jap. J. Herpetol. 13: 15-20.

Joshy, S. H., Rahiman, M. A., Sreepada, K. S. and Gururaj, M. E. 1999. Karyotypes of six species of anurans from the Western Ghats, South India. Nucleus 42: 73-76.

Kobayashi, M. 1962. Studies on reproductive isolation mechanism in Brown frogs. II. Hybrid sterility. J. Sci. Hiroshima Univ., Ser. B., Div. 1,20: 157-179.

Koref-Santibanez, S. 1979. The karyotypes of Rana lessona Camerano, Rana ridibunda Pallas and the hybrid form Rana "esculenta" Linne (Anura). Mitt. Zool. Mus. Berlin. 55: 115-124.

Levan, A., Fredga, K. and Landberg, A. 1964. Nomenclature for centromeric position on chromosomes. Hereditas 52: 201-220.

Mittal, O. P. and Sawhney, V. 1971. Chromosomes from cells of the intestinal mucosa of two Indian anurans. Mamma. Chrom. Newslet. 12: 26.

Miura, I. 1994. Sex chromosome differentiation in the Japanese brown frog, Rana japonica. 1. Sex-related heteromorphism of the distribution pattern of constitutive heterochromatin in chromosome no. 4 of the Wakuya population. Zool. Sci. 11: 797-806.

Natarajan, R. 1958. Contributions to the cytology of Indian Anura (Amphibia): studies on the spermatogenesis of three species of Rana (Ranidae). J. Zool. Soc. India. 10: 4-14.

Nishioka, M., Okumoto. H., Ueda, H. and Ryuzaki, M. 1987. Karyotypes of brown frogs distributed in Japan, Korea, Europe and North America. Sci. Rep. Lab. Amphi Biol. Hiroshima Univ. 9: 165-212.

Odierna, G., Vences, M., Aprea, G., Lotters, S. and Andreone, F. 2001. Chromosome data for Malagasy poison frogs (Amphibia: Ranidae: Mantella) and their bearing on the taxonomy and phylogeny. Zool. Sci. 18: 505-514.

Omura, T. 1967. A method for chromosome preparation from amphibian bone marrow cells without in vitro culture and centrifugation. Zool. Mag. 76: 239-240.

Sanjay, M. 1997. All Indian amphibian assessed according to new IUCN categories. Froglog 2: 1-8.

Schmid, M. 1978. Chromosome banding in Amphibia. II. Constitutive heterochromatin and nucleolus organizer regions in Ranidae, Microhylidae and Rhacophoridae. Chromosoma. 68: 131-148.

- 1980. Chromosome banding in amphibia. IV. Differentiation of GC- and AT-rich chromosome regions in anura. Chromosoma 77: 83-103.

Seto, T. 1964. The karyotype of Hyla arborea japonica with some remarks on heteromorphism of the sex chromosomes. J. Fac. Sci. Hokkido Univ., Ser. VI. 15: 366-373.

- 1965. Cytogenetic studies in lower vertebrates. II. Karyological studies of several species of frogs (Ranidae). Cytologia 30: 437-446.

Sharma, G. P., Parshad, R. and Sethi, A. 1966. Chromosomes in the common frog, Rana tigrina. Proc. 53rd Ind. Sci. Cong. IV: 320.

Sumner, A. T. 1972. A simple technique for demonstrating centromeric heterochromatin. Exp. Cell. Res. 75: 304-306.

Vences, M., Wanke, S., Odierna, G., Kosuch, J. and Veith, M. 2000. Molecular and karyologic data on the South Asian ranid genera Indirana, Nyctibatrachus, Nannophrys (Anura: Ranidae). Hamadryad 25: 75-82.

Wickbom, T. 1945. Cytological studies on Dipnoi, Urodela, Anura, and Emys. Hereditas 31: 241-346.

Witschi, E., Kodani, M. and Mikamo. 1958. Comparative study of the chromosomes of European, American and Japanese frogs. Anat. Rec. 131: 610.

Yadav, J. S. and Pillai, R. K. 1975. Somatic karyotypes of two species of Indian frogs (Anura: Amphibia). Cytobios 13: 109-115.

— and — 1976. Female heterogamety in two species of Rana (Ranidae: Anura). Chrom. Inform. Serv. 20: 9-11. 